\title{
A Prediction Model for Postoperative Pulmonary Complication in Pulmonary Function-Impaired Patients Following Lung Resection
}

\author{
Xiaowei Mao $\mathbb{1 D}^{1,2, *}$ \\ Wei Zhang ${ }^{1,3, *}$ \\ Yi-Qian $\mathrm{Ni}^{\prime}$ \\ Yanjie Niu' \\ Li-Yan Jiang'
}

'Pulmonary and Critical Care Medicine, Shanghai Jiao Tong University, Shanghai Chest Hospital, Shanghai, People's Republic of China; ${ }^{2}$ Pulmonary and Critical Care Medicine, Sir Run Run Shaw Hospital, School of Medicine, Zhejiang University, Hangzhou, People's Republic of China; ${ }^{3}$ Department of Internal Medicine, American-Sino Women's \& Children's Hospital, Shanghai, People's Republic of China

*These authors contributed equally to this work
Correspondence: Li-Yan Jiang Pulmonary and Critical Care Medicine, Shanghai Chest Hospital, Shanghai Jiao Tong University, No. 24I West Huaihai Road, Shanghai, People's Republic of China

$\mathrm{Tel} / \mathrm{Fax}+86$ 2I-22200000-380 I

Email jiang_liyan2000@126.com
Purpose: Most patients with lung cancer have impaired pulmonary function. Single pulmonary function parameters have been suggested as good indices for predicting postoperative pulmonary complications (PPC). The purpose of this retrospective study was to construct a prediction model, including more than one pulmonary function parameter, for better prediction of PPC in patients with lung cancer and impaired pulmonary function.

Patients and Methods: Our database of patients who underwent lung resection for non-small cell lung cancer was reviewed and those with impaired pulmonary function were enrolled. Clinical data, including PPC, were recorded. Univariate and logistic regression analyses were applied to explore potential predictors and a prediction model constructed based on the results of logistic regression.

Results: Patients with impaired pulmonary function $(n=124)$ were enrolled. Most patients were male, current smokers, $>60$ years old, and had adenocarcinoma and mild ventilatory dysfunction or diffusion dysfunction. In univariate analysis, we identified six pulmonary function parameters that differed significantly between the PPC and non-PPC groups. Receiver operating characteristic curves were used to determine the best cutoff values. In logistic regression, only forced expiratory volume in 1 second/forced vital capacity (FEV1/FVC\%), peak expiratory flow (PEF\%), and post predictive operation (ppo)-FEV1\% remained significant. Based on these results, we constructed a prediction model for PPC including FEV1/FVC\%, PEF\%, and ppo-FEV1\%, which had an good diagnostic performance of, with $76.7 \%$ sensitivity and $67.6 \%$ specificity.

Conclusion: Our prediction model, including the pulmonary function parameters, FEV1/FVC\%, $\mathrm{PEF} \%$, and ppo-FEV1\%, shows excellent performance for predicting PPC in patients with lung cancer and impaired pulmonary function following resection, and has potential for wide application in clinical practice.

Keywords: non-small-cell lung, retrospective studies, forced expiratory volume, logistic models, respiratory function tests

\section{Introduction}

Lung cancer is the leading cause of cancer-related deaths in China and elsewhere in the world. ${ }^{1,2}$ Surgery is the optimal treatment for early-stage lung cancer, particularly non-small cell lung cancer. ${ }^{4}$ The death rate in the 30 days after lung resection is approximately $4.4 \%$, and the rate of postoperative pulmonary complications (PPC) is around $20 \%-40 \%$.

Good pulmonary and heart function is necessary for lung cancer surgery. The American College of Chest Physicians (ACCP) also suggests that careful preoperative 
physiological assessment is useful for identifying patients for whom surgery is appropriate. ${ }^{6}$ Several tests are usually conducted before pulmonary resection, including pulmonary function test, cardiopulmonary exercise test, pulmonary ventilation and perfusion scan, and impulse oscillation, among others; overall, pulmonary function is key. However, patients with lung cancer may have impaired pulmonary function. First, most patients with lung cancer are elderly, have a history of smoking, and have chronic respiratory comorbidities. $7,8,10$ Second, the tumor may block the bronchus and the tumor cell embolus can also block blood vessels, leading to unbalanced ventilation and blood flow. ${ }^{10}$ Third, respiratory movement depends on thoracic integrity, which is destroyed by the surgery itself. ${ }^{11}$ Fourth, nerve damage, pain caused by surgical incision, and the central inhibition generated by anesthesia impair respiratory movement and cause PPC. ${ }^{12}$

The rate of PPC is established as related to impaired pulmonary function. ${ }^{13-17}$ Alam et al reported significant differences in the percentages of predicted forced vital capacity (FVC) and forced expiratory volume in 1 second (FEV1) in patients who developed atelectasis and respiratory tract infection following cardiac surgery. ${ }^{14}$ Shin et al found that diffusing capacity of the lung for carbon monoxide (DLco) value before neoadjuvant concurrent chemoradiotherapy was significantly associated with risk of PPC. ${ }^{15}$ Further, peak expiratory flow (PEF) and maximal ventilatory volume (MVV) may be valuable for predicting PPC following lung surgery. ${ }^{16,17}$

Previous studies to identify factors influencing PPC were clearly limited by the inclusion of only single potentiallyassociated indices. Prediction models are currently widelyapplied in clinical practice because they are concise and clear, and always involve more than one index for risk calculation. ${ }^{18,19}$ Here, we conducted a retrospective study to constructed a prediction model based on pulmonary function parameters for better prediction of PPC in patients who underwent lung cancer resection with impaired pulmonary function.

\section{Methods}

\section{Patient Selection}

We reviewed our database, which includes basic clinical data and PPC data from patients who underwent lung resection in Shanghai Chest Hospital, Shanghai Jiao Tong University in 2012 and 2013. The inclusion criteria were: (1) age 18-80 years; (2) underwent lung resection in Shanghai Chest Hospital, Shanghai Jiao Tong University; (3) pulmonary function test performed within
1 week before surgery; (4) impaired pulmonary function, according to the guidelines edited by Chinese Thoracic Society: FEV $1<80 \%$ or DLco $<80 \% .^{20,21}$ The exclusion criteria were: (1) incomplete clinical data for analysis; (2) final pathologic diagnosis not non-small cell lung cancer; (3) contraindications for pulmonary function examination, (4) severe cardiac insufficiency determined by electrocardiogram or echocardiography; (5) had previously undergone lung resection; (6) other severe cerebrovascular diseases, or other conditions, that exclude lung resection. Clinical data were extracted, including: age, sex, smoking history, main comorbidities, surgery type, pathologic diagnosis, and details of PPC.

\section{Ethics Statement}

The Ethics Committee of Shanghai Chest Hospital approved this study (KS1924). All the patients provided signed informed consent. All authors followed the Declaration of Helsinki.

\section{Pulmonary Function Test}

Pulmonary function tests were conducted using a Jaeger MasterScreen Body Plethysmograph. All patients underwent routine pulmonary function examination within one week before surgery. Before testing, the instrument was calibrated to meet the appropriate use standard. Pulmonary function curves were repeated at least three times (maximum five times) for each patient. Primary observation indices were: FVC\%, MVV, FEV1\%, FEV1/ $\mathrm{FVC} \%$, and PEF. To control for the influence of age, height, and weight on lung function, detection indices are expressed as the percentage of the measured value relative to that of the predicted value. ${ }^{22}$ Normal reference values were those for the Shanghai area. ${ }^{23}$ Post predictive operation (ppo) FEV1\% and carbon monoxide diffusing capacity (DLCO\%) were also calculated, according to the formula developed by Juhl and Frost. ${ }^{24}$

According to the pulmonary function guidelines formulated by the Chinese Medical Association, patients were classified as follows: normal function, ventilation dysfunction (including restrictive ventilation dysfunction, obstructive ventilation dysfunction, mixed ventilation dysfunction), or diffuse dysfunction. ${ }^{20-22,25}$

\section{Postoperative Pulmonary Complications}

PPC were defined as occurring within 1 month after lung resection, as follows: (1) Pneumonia characterized by new lung infiltration on imaging examination, and any of the 
following: A. fever (body temperature $\geq 38^{\circ} \mathrm{C}$ ) lasting for more than 5 days, B. white blood cell count $>10.5 \times 10^{9 /}$ L, C. antibiotic upgrade treatment or antibiotic application for > 7 days; (2) Atelectasis; (3) Long term mechanical ventilation, due to postoperative respiratory failure (mechanical ventilation time $>48 \mathrm{~h}$ ); (4) Secondary tracheal intubation; (5) Long-term ( $>7$ days) drainage because of air leakage or persistent pleural effusion; (6) Bronchopleural fistula; (7) Pulmonary embolism; (8) Other pulmonary complications. $^{26,27}$

\section{Statistics}

SPSS 20.0 software (IBM co. 1td) was used to perform statistical analyses. Measurement data were expressed as mean $\pm \mathrm{SD}$. Comparisons between groups were conducted by one-way ANOVA and $t$-test. Categorical data were analyzed by Pearson $\chi^{2}$ test and Fisher exact probability test. Receiver operating characteristic (ROC) curves were applied to assess the diagnostic value of each parameter, and the Youden index was used to determine the best cutoff value. Correlation between postoperative complications and pulmonary function indices was analyzed by logistic regression. Values of $p<0.05$ were considered significant. Prediction model construction followed previous publications. ${ }^{28,29}$

\section{Results}

\section{Patient Characteristics}

A total of 124 patients met the inclusion criteria and were enrolled in this study. Among all patients, most were male $(77 \%),>60$ years old $(61 \%)$, current smokers $(47 \%)$, and suffered adenocarcinoma (53\%). Of all patients, 91 had ventilatory dysfunction and 84 patients had diffusion dysfunction or both. Patient characteristics are presented in Table 1. In total, 34 patients with 42 PPC were included in our study, representing a PPC incidence of $27 \%$. The most frequent PPC were long-term drainage tube and pneumonia. Six patients had more than one PPC. PPC details are provided in Table 2.

\section{Univariate Analysis of Patient Characteristics Associated with Postoperative Pulmonary Complications}

Univariate analysis of the relationships between patient characteristics and PPC demonstrated that sex, FEV1\%, FEV1/FVC\%, PEF\%, MVV\%, and ppo-FEV1\% differed significantly between the PPC and non-PPC groups. Analysis by sex showed that males were more likely to
Table I Patient Characteristics

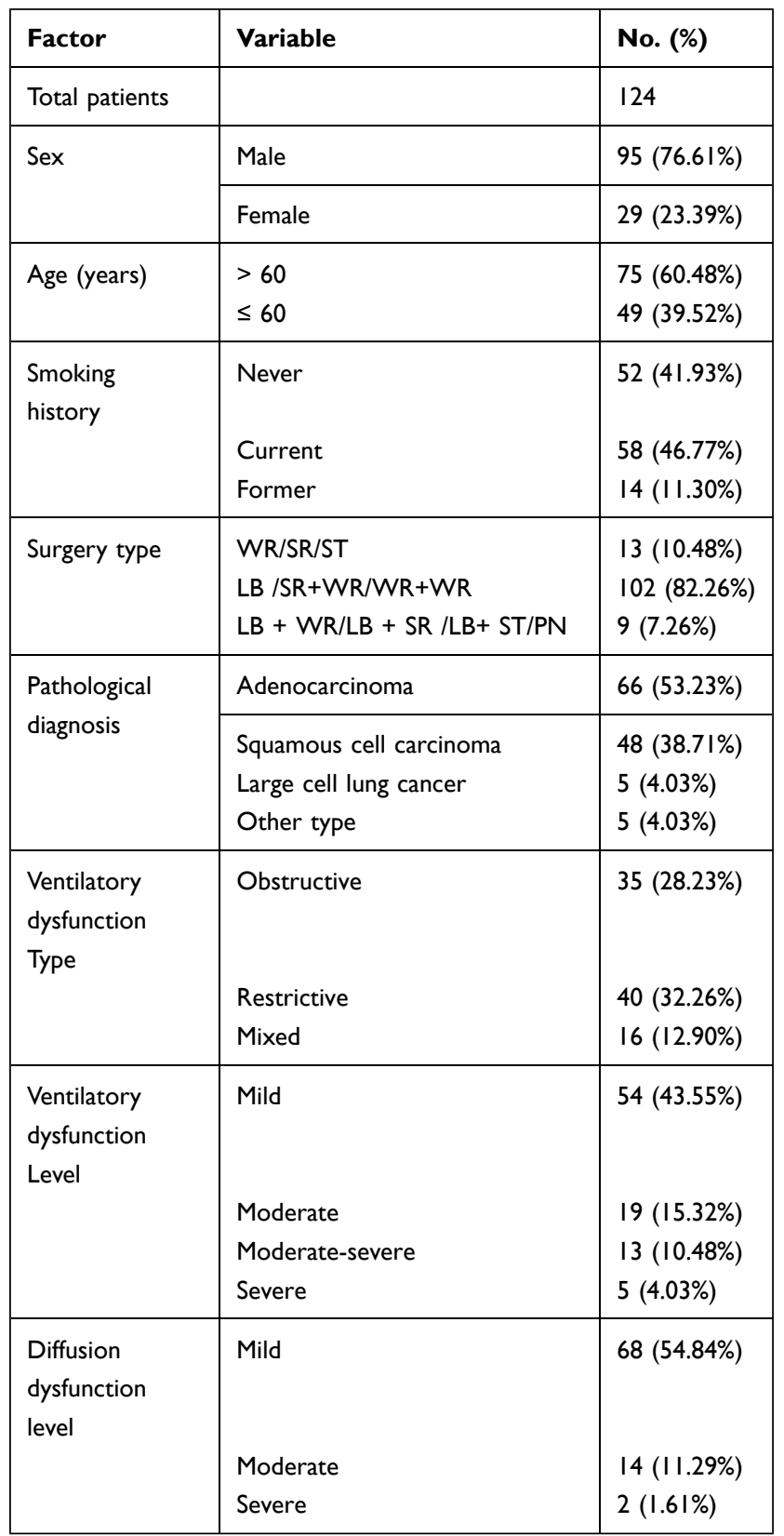

Abbreviations: WR, wedge resection; SR, sleeve resection; ST, segmentectomy; $\mathrm{LB}$, lobectomy; PN, pneumonectomy.

have PPC than females. Further, pulmonary function was worse in the PPC than the non-PPC group (Table 3). Next, we constructed ROC curves to determine the optimal cutoff values and found that area under the curve (AUC) values for $\mathrm{FEV} 1 / \mathrm{FVC} \%, \mathrm{FEV} 1 \%, \mathrm{PEF} \%, \mathrm{MVV} \%$, and ppo-FEV1\% were all $>0.5$, with $\mathrm{p}<0.05$ (Figure 1). The Youden index was used to determine optimal cutoff values. Detailed cutoff, sensitivity, specificity, and diagnostic yield values for each parameter are presented in Supplementary Table 1. 
Table 2 Postoperative Pulmonary Complications

\begin{tabular}{|l|l|}
\hline PPC & No. (\%) \\
\hline Pneumonia & $13(30.95 \%)$ \\
Atelectasis & $2(4.76 \%)$ \\
Mechanical ventilation $>48 \mathrm{~h}$ & $2(4.76 \%)$ \\
$\begin{array}{l}\text { Re-intubation } \\
\text { Long-term drainage tube }\end{array}$ & $\mathrm{I}(2.38 \%)$ \\
Pneumorrhagia & $23(54.77 \%)$ \\
\hline Total events & $\mathrm{I}(2.38 \%)$ \\
\hline \multicolumn{1}{l}{ I event } & $\mathbf{4 2 ( 1 0 0 \% )}$ \\
\hline Total patients & $28(82.35 \%)$ \\
\hline
\end{tabular}

Abbreviation: PPC, postoperative pulmonary complications.

\section{Logistic Regression Model of Factors} Associated with Postoperative Pulmonary Complications

Subsequently, we constructed a logistic regression model including the five pulmonary function parameters and sex. Only FEV1/FVC\%, PEF\%, and ppo-FEV1 remained significant and were included in the model (Table 4).
Based on those findings, we constructed a points system including the three parameters, FEV1/FVC\%, PEF, and ppoFEV1\%. Each parameter had two options, low and high, based on ROC curve analysis (Supplementary Table 1), and each option of pulmonary parameter was corrected by a defined point. Score sheets for prediction of PPC using the $\mathrm{FEV} 1 / \mathrm{FVC} \%$, PEF, and ppo-FEV1\% categorical variables were developed based on the coefficients calculated using the logistic regression model. ${ }^{29}$ Hence, we established a prediction model for risk of PPC after lung resection in patients with impaired pulmonary function using the three clinically significant risk factors identified by multivariate analysis. The finally prediction model is as follows:

$$
\text { PPCrate }=\frac{1}{1+\exp (0.3 \times \text { totalpoints }-1.108)}
$$

(Table 5) Using this system, we could calculate a patient's score and use it to determine their corresponding PPC risk. Further, we drew a heat map of the three parameters, which facilitated easy determination of patient PPC risk levels according to color (Figure 2).

Table 3 Univariate Analysis of Differences Between the PPC and Non-PPC Groups

\begin{tabular}{|c|c|c|c|c|}
\hline Factor & Variable & PPC & Non-PPC & P-value \\
\hline \multirow[t]{2}{*}{ Sex } & Male & 31 & 64 & 0.018 \\
\hline & Female & 3 & 26 & \\
\hline \multirow[t]{2}{*}{ Age (years) } & $\leq 60$ & 12 & 37 & 0.681 \\
\hline & $>60$ & 22 & 53 & \\
\hline \multirow[t]{3}{*}{ Smoking history } & Never & 13 & 39 & 0.875 \\
\hline & Current & 17 & 41 & \\
\hline & Former & 4 & 10 & \\
\hline \multirow[t]{3}{*}{ Surgery type } & WR/SR/ST & 3 & 10 & 0.465 \\
\hline & $L B / S R+W R / W R+W R$ & 30 & 72 & \\
\hline & $\mathrm{LB}+\mathrm{WR} / \mathrm{LB}+\mathrm{SR} / \mathrm{LB}+\mathrm{ST} / \mathrm{PN}$ & I & 8 & \\
\hline FEVI\% & & 68.11 & 77.64 & $<0.001$ \\
\hline FVC\% & & 78.94 & 81.96 & 0.236 \\
\hline FEVI/FVC\% & & 66.42 & 74.31 & $<0.001$ \\
\hline DLCO\% & & 71.43 & 75.60 & 0.160 \\
\hline PEF\% & & 67.032 & 78.289 & 0.001 \\
\hline MVV\% & & 91.03 & 99.95 & 0.021 \\
\hline PPo-FEVI\% & & 51.58 & 60.58 & $<0.001$ \\
\hline Ppo-DLCO\% & & 54.06 & 58.83 & 0.073 \\
\hline \multicolumn{2}{|c|}{ Number of segments removed } & 4.62 & 4.21 & 0.237 \\
\hline
\end{tabular}

Abbreviations: PPC, post pulmonary complications; WR, wedge resection; SR, sleeve resection; ST, segmentectomy; LB, lobectomy; PN, pneumonectomy; FEVI, Forced expiratory volume in the first second; FVC, forced vital capacity; DLCO, carbon monoxide diffusing capacity; PEF, peak expiratory flow; MVV, maximal ventilatory volume; Ppo, post-pulmonary operation. 
Table 4 Logistic Regression Analysis

\begin{tabular}{|l|l|l|l|}
\hline Risk Factor & P value & OR & $\mathbf{9 5 \%} \mathbf{~ C l}$ \\
\hline FEVI/FVC\% & 0.018 & 0.319 & $0.124,0.819$ \\
PEF & 0.032 & 0.293 & $0.096,0.897$ \\
PPO-FEVI & 0.022 & 0.213 & $0.057,0.802$ \\
\hline
\end{tabular}

Abbreviations: FEVI, Forced Expiratory Volume in the first second; FVC, forced vital capacity; PEF, peak expiratory flow; PPo, post-pulmonary operation; OR, odds ratio; $\mathrm{Cl}$, confidence interval.

The predictive performance of our model was assessed by ROC analysis, which demonstrated that the AUC value of the model was 0.793 (95\% confidence interval, $0.701-$ $0.885 ; \mathrm{P}<0.001)$; hence the model had good predictive performance and sensitivity and specificity values of $76.7 \%$ and $67.6 \%$, respectively (Figure 3 ).

\section{Discussion}

Lung cancer causes the most cancer-related deaths in China and worldwide, ${ }^{1,2}$ and approximately $80 \%$ of cases are nonsmall cell lung cancer (NSCLC). ${ }^{30}$ Radical operation is a valuable strategy for multidisciplinary teams to treat patients with early-stage NSCLC. ${ }^{4}$ Patients with lung cancer are usually elderly, have a history of smoking, and have cardiovascular or respiratory comorbidities, and those factors increase the risk of PPC incidence. ${ }^{10,31}$ Although surgery and nursing techniques have advanced over the last decade, PPC still occur in $20-30 \%$ patients. $^{32}$ As mentioned above, pulmonary function also influences the occurrence of PPC, and

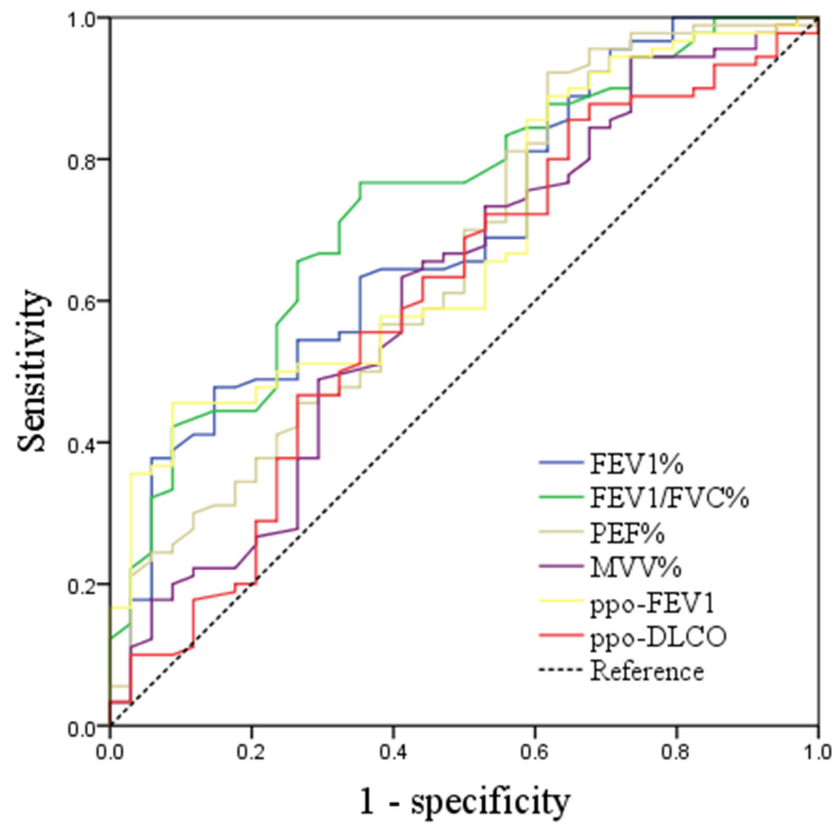

Figure I ROC curves of pulmonary function parameters.
Table 5 Postoperative Pulmonary Complications Score System

\begin{tabular}{|c|c|c|c|}
\hline Item & Classification & Cutoff (\%) & Points \\
\hline \multirow[t]{2}{*}{ FEVI/FVC\% } & High & $>68.25$ & 4 \\
\hline & Low & $<68.25$ & 0 \\
\hline \multirow[t]{2}{*}{ PEF\% } & High & $>56.8$ & 4 \\
\hline & Low & $<56.8$ & 0 \\
\hline \multirow[t]{2}{*}{ PPo-FEVI\% } & High & $>61.65$ & 5 \\
\hline & Low & $<61.65$ & 0 \\
\hline
\end{tabular}

Abbreviations: FEVI, forced expiratory volume in the first second; FVC, forced vital capacity; PEF, peak expiratory flow; ppo, post-pulmonary operation.

most patients with NSCLC have impaired pulmonary function. In this study, we focused on the predictors of impaired pulmonary function in patients with NSCLC.

In our cohort of enrolled patients with impaired pulmonary function, the incidence of PPC was approximately $27 \%$, which is higher than that in previous reports. Overall, pneumonia and long-term air leakage were the most common PPC. In univariate analysis, sex, FEV1\%, FEV1/FVC\%, PEF\%, MVV\%, and ppo-FEV1\% were identified as predictors of PPC. In clinical practice, we classify abnormal pulmonary function according to indications including FEV1\%, FVC\%, FEV1/FVC\%, and DLCO $\%$, among others. Several studies have demonstrated that the incidence of PPC increases with severe impaired pulmonary function. ${ }^{13-17,33,34} \mathrm{FEV} 1 / \mathrm{FVC} \%$ reflects airway obstruction and airway resistance, hence significant decreases in this parameter indicate that patients have pulmonary ventilation dysfunction and the possibility of pulmonary complications after lung resection is increased. Fernandes et al reported that $\mathrm{FEV} 1 / \mathrm{FVC} \%<60 \%$ is a predictor of postoperative mortality and PPC. ${ }^{35}$ Further, FEV1\% can be a predictor of PPC. Kroenke et al found that patients with poor FEV1\% experience higher rates of

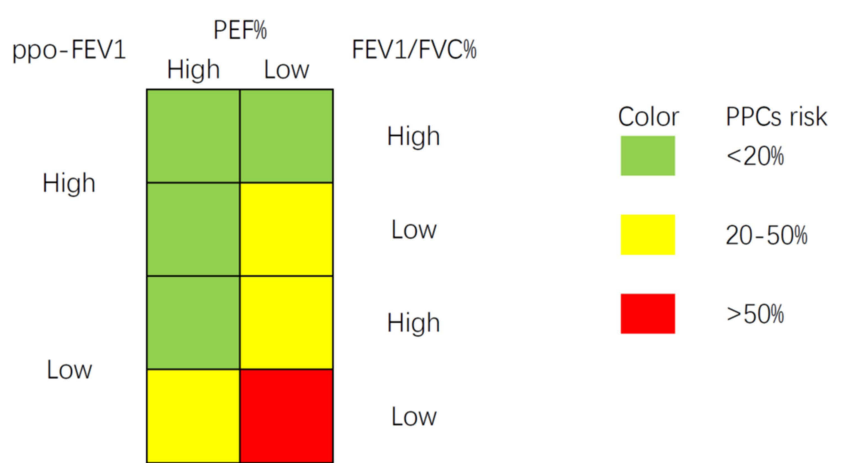

Figure 2 Heat map of association of different pulmonary functions and postoperative pulmonary complications. 


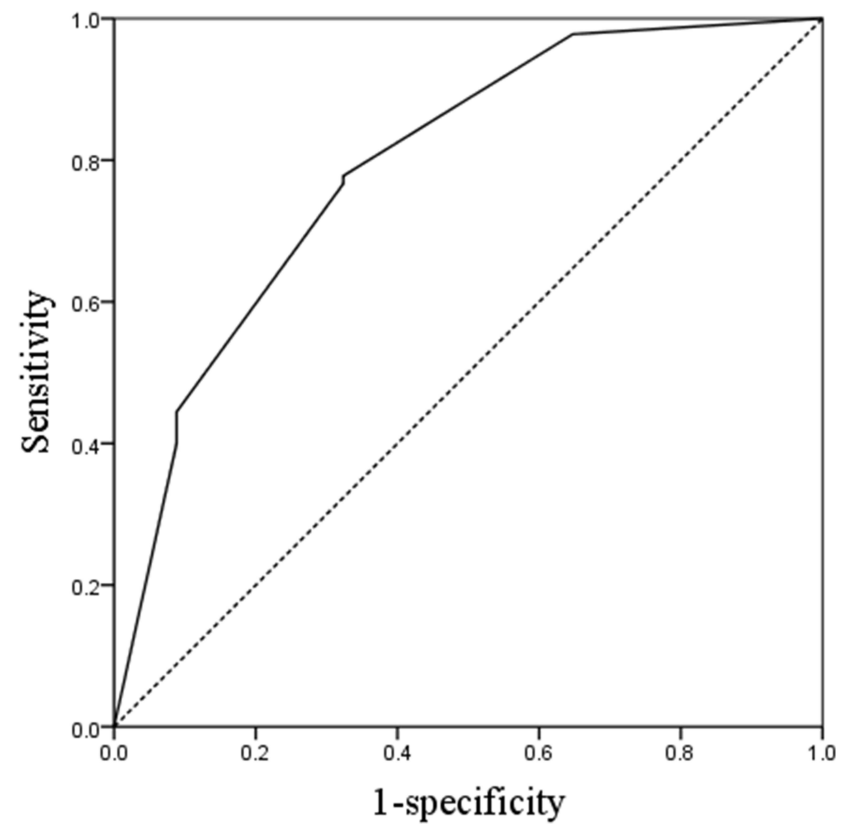

Figure 3 ROC curve of the postoperative pulmonary complications prediction model.

serious pulmonary complications and death. ${ }^{36}$ PEF is a useful parameter that reflects the strength of respiratory muscles and whether the airway is blocked, ${ }^{20}$ while MVV $\%$ reflects the elasticity of thoracic lung tissue, airway resistance, and respiratory muscle strength, ${ }^{20}$ these two parameters are related to respiratory muscle strength, which affects cough following surgery. DLCO $\%$ is an index that reflects lung diffusion function, and Sandri et al found that patients with DLCO $\%<50 \%$ have a higher incidence of cardiopulmonary complications and longer postoperative stay. ${ }^{37}$ Further, Stamenovic concluded that better lung function (FEV1 $>72 \%$, DLCO > $57 \%$ ) is associated with improved patient outcomes. ${ }^{38}$

In this study, we did not find that the number of lung segments removed influenced PPC rates. Values of ppoFEV1\% and ppo-DLCO $\%$ are calculated based on the number of segments removed and preoperative pulmonary function; these two parameters reflect the pulmonary reserve following lung resection, and e identified ppoFEV $1 \%$ as a good predictor of PPC. ${ }^{39}$ Some reports have suggested that ppo-FEV1\% is more clinically meaningful. ${ }^{40,41}$ Clinicians will likely decide to remove fewer segments from a patient with severely abnormal pulmonary function attending for lung resection. ${ }^{42,43}$

Previous studies have only explored the predictive value of single pulmonary function parameters, while methods used to determine diagnostic value are more modern. Inclusion of several risk factors in a model can produce synergistic effects; thus, combining two or more parameters can improve diagnostic performance. Based on previous findings, we conducted logistic regression analysis and found that only FEV1/FVC\%, PEF\%, and ppoFEV $1 \%$ remained clinically significant. Using those three parameters, we constructed a prediction model to evaluate the PPC rate of patients with NSCLC and abnormal pulmonary function. This model includes several pulmonary function parameters, both preoperative and postoperative, that can be used to directly evaluate the risk of PPC before operation. The performance of this model is excellent, as demonstrated by the results of ROC analysis in this study. With the help of this model, it is easy to predict the probability of PPC after lung resection in patients with impaired pulmonary function. The model indicates that the PPC rate of patients with all low values for all indices was 24 times higher than that of patients with all high index values. For each patient, we could determine the PPC rate from Table 6 after calculating their total score. Further, the heat map generated in this study also provides a simple method to evaluate the likelihood of PPC after surgery. Red blocks indicate that the patient has a high risk of developing PPC, whereas green blocks indicate low risk. This model is simple and easy to apply in daily clinical practice. If the predictive probability is high, or the corresponding heatmap is yellow or red, then the patient has a high risk of developing PPC and should be closely monitored during the whole postoperative period. Hence, it is possible to identify patients at high risk of postoperative PPC. If the predictive probability is low, or the corresponding heatmap is green, then the patient has a low risk of developing PPC, thus routine medical care is sufficient, which could save valuable medical resources.

Our study also has some limitations. First, this is a retrospective study; therefore, although we screened patients without bias and excluded those with incomplete data, selection bias could not be avoided. Second, we judged the PPC categories according to medical and examination records. Some PPC records were missing due to mistakes in the records. Third, conventional spirometry is insensitive for detecting early damage to the small airways

Table 6 Postoperative Pulmonary Complications Risk Rate

\begin{tabular}{|l|l|l|l|l|l|l|}
\hline Total Points & 0 & 4 & 5 & 8 & 9 & 13 \\
\hline PPC risk & 0.73 & 0.42 & 0.34 & 0.15 & 0.11 & 0.03 \\
\hline
\end{tabular}


and assessing the distribution of ventilation. The new technique, multiple-breath washout, is valuable for evaluating peripheral airway function and ventilation homogeneity, and is sensitive in detecting lung complications; ${ }^{44}$ however, due to equipment limitations, we did not conducted this type of analysis.

\section{Conclusion}

In summary, our prediction model, including the parameters, FEV1/FVC\%, PEF\%, and ppo-FEV1\%, can be widely applied in clinical practice. More prospective studies are required to further verify the effectiveness of this model.

\section{Acknowledgments}

This work was support by the National Key Research and Development Program of China: 2018 YFC1313600 (Jiang LY), Chinese Society of Clinical Oncology (CSCO): Y-2019AZZD-0038 (Jiang LY).

\section{Disclosure}

The authors declare that they have no conflicts of interest related to this work.

\section{References}

1. Bray F, Ferlay J, Soerjomataram I, et al. Global cancer statistics 2018: GLOBOCAN estimates of incidence and mortality worldwide for 36 cancers in 185 countries. CA Cancer J Clin. 2018;68:394-424.

2. Chen W, Zheng R, Baade PD, et al. Cancer statistics in China, 2015. CA Cancer J Clin. 2016;66(2):115-132. doi:10.3322/caac.21338

3. Baltayiannis N, Chandrinos M, Anagnostopoulos D, et al. Lung cancer surgery: an up to date. $J$ Thorac Dis. 2013;5(Suppl 4):S425-39.

4. Strand TE, Rostad H, Damhuis RA, et al. Risk factors for 30-day mortality after resection of lung cancer and prediction of their magnitude. Thorax. 2007;62:991-997.

5. Tabutin M, Couraud S, Guibert B, et al. Completion pneumonectomy in patients with cancer: postoperative survival and mortality factors. $J \quad$ Thorac Oncol. 2012;7(10):1556-1562. doi:10.1097/ JTO.0b013e31826419d2

6. Brunelli A, Anthony WK, Kenneth IB, et al. Physiologic evaluation of the patient with lung cancer being considered for resectional surgery: diagnosis and management of lung cancer, 3rd ed: American College of Chest Physicians evidence-based clinical practice guidelines. Chest. 2013; 143:e166s-e190s.

7. Schulte T, Schniewind B, Dohrmann P, et al. The extent of lung parenchyma resection significantly impacts long-term quality of life in patients with non-small cell lung cancer. Chest. 2009;135 (2):322-329. doi:10.1378/chest.08-1114

8. Gullón JA, Suárez I, Medina A, et al. Carcinoma de pulmón: cambios en epidemiología y supervivencia. Rev Clin Esp. 2012;212(1):18-23. doi:10.1016/j.rce.2011.06.004

9. Jones LW. Physical activity and lung cancer survivorship. In: Courneya KS, Friedenreich CM, editors. Physical Activity and Cancer. Recent Results in Cancer Research. Berlin, Heidelberg: Springer; Vol. 186, 2011:255-274.
10. Li CX, Zhou L, Jiang ZH, et al. The detection of lung function in patients with lung cancer. J Clin Pulm Med. 2006;11:734-735.

11. Moser G, Koppensteiner R, Eckersberger F, et al. Postoperative complication rate of thoracotomy in patients with normal and abnormal pulmonary function. Wien Klin Wochenschr. 1993;105:71-75.

12. Boushy SF, Billig DM, North LB, et al. Clinical course related to preoperative and postoperative pulmonary function in patients with bronchogenic carcinoma. Chest. 1971;59(4):383-391. doi:10.1378/ chest.59.4.383

13. Radu DM, Jauréguy F, Seguin A, et al. Post-operative pneumonia after major pulmonary resections: an unsolved problem in thoracic surgery. Ann Thorac Surg. 2007;84:1669-1673.

14. Alam M, Shehzad MI, Hussain S, et al. Spirometry assessment and correlation with postoperative pulmonary complications in cardiac surgery patients. Cureus. 2020;12:e11105.

15. Shin S, Choi YS, Jung JJ, et al. Impact of diffusing lung capacity before and after neoadjuvant concurrent chemoradiation on postoperative pulmonary complications among patients with stage IIIA/ N2 non-small-cell lung cancer. Respir Res. 2020;21(1):13. doi:10.1186/s12931-019-1254-0

16. Kim SK, Chang J, Ahn CM, et al. Relationship between the result of preoperative pulmonary function test and postoperative pulmonary complications. J Korean Med Sci. 1987;2(1):71-74. doi:10.3346/ jkms.1987.2.1.71

17. Lai Y, Wang X, Li P, et al. Preoperative peak expiratory flow (PEF) for predicting postoperative pulmonary complications after lung cancer lobectomy: a prospective study with 725 cases. J Thorac Dis. 2018;10(7):4293-4301. doi:10.21037/jtd.2018.07.02

18. Collins GS, Reitsma JB, Altman DG, et al. Transparent reporting of a multivariable prediction model for individual prognosis or diagnosis (TRIPOD): the TRIPOD statement. BMJ. 2015;350:g7594. doi:10.1136/bmj.g7594

19. Grant SW, Collins GS, Nashef SAM. Statistical Primer: developing and validating a risk prediction model. Eur J Cardiothorac Surg. 2018;54(2):203-208. doi:10.1093/ejcts/ezy180

20. Chinese Thoracic Society. Guidelines for pulmonary function tests (Part 2) -Spirometer examination. Zhonghua Jie He He Hu Xi Za Zhi. 2014;37:481-486.

21. Chinese Thoracic Society. Guidelines for pulmonary function tests Pulmonary diffusion function examination. Zhonghua Jie He He Hu Xi Za Zhi. 2015;38:164-169.

22. Chinese Thoracic Society. Guidelines for pulmonary function tests (Part 1) - Summary and general requirements. Zhonghua Jie He He Hu Xi Za Zhi. 2014;37:402-405.

23. Stocks J, Quanjer PH. Reference values for residual volume, functional residual capacity and total lung capacity. ATS Workshop on lung volume measurements. official statement of the European respiratory society. Eur Respir J. 1995;8(3):492-506. doi:10.1183/ 09031936.95.08030492

24. Markos J, Mullan BP, Hillman DR, et al. Preoperative assessment as a predictor of mortality and morbidity after lung resection. Am Rev Respir Dis. 1989;139(4):902-910. doi:10.1164/ajrccm/139.4.902

25. Chinese Thoracic Society. Guidelines for pulmonary function tests Lung volume examination. Zhonghua Jie He He Hu Xi Za Zhi. 2015;38:255-260.

26. Glogowska O, Glogowski M, Szmit S. Intensive rehabilitation as an independent determinant of better outcome in patients with lung tumors treated by thoracic surgery. Arch Med Sci. 2017;13:1442-1448. doi:10.5114/aoms.2016.60706

27. Lai YT, Huang J, Yang M, et al. Seven-day intensive preoperative rehabilitation for elderly patients with lung cancer: a randomized controlled trial. J Surg Res. 2017;209:30-36. doi:10.1016/j. jss.2016.09.033

28. Woodward M, Tunstall-Pedoe H, Peters SA. Graphics and statistics for cardiology: clinical prediction rules. Heart. 2017;103(7):538-545. doi:10.1136/heartjnl-2016-310210 
29. Wilson PW, D'Agostino RB, Levy D, et al. Prediction of coronary heart disease using risk factor categories. Circulation. 1998;97 (18):1837-1847. doi:10.1161/01.CIR.97.18.1837

30. Herbst RS, Heymach JV, Lippman SM. Lung cancer. $N$ Engl J Med. 2008;359(13):1367-1380. doi:10.1056/NEJMra0802714

31. Brunelli A, Kim AW, Berger KI, et al. Physiologic evaluation of the patient with lung cancer being considered for resectional surgery. Chest. 2013;143:e166-e195.

32. Lee JY, Jin SM, Lee CH, et al. Risk factors of postoperative pneumonia after lung cancer surgery. J Korean Med Sci. 2017;26 (8):979-984. doi:10.3346/jkms.2011.26.8.979

33. Kim ES, Kim YT, Kang CH, et al. Prevalence of and risk factors for postoperative pulmonary complications after lung cancer surgery in patients with early-stage COPD. Int J Chron Obstruct Pulmon Dis. 2016;11:1317-1326. doi:10.2147/COPD.S105206

34. Kneuertz PJ, D'Souza DM, Moffatt-Bruce SD, et al. Robotic lobectomy has the greatest benefit in patients with marginal pulmonary function. J Cardiothorac Surg. 2018;13(1):56. doi:10.1186/s13019018-0748-z

35. Fernandes EO, Teixeira C, Silva LC. Thoracic surgery: risk factors for postoperative complications of lung resection. Rev Assoc Med Bras. 2011;57(3):292-298. doi:10.1590/S0104-42302011000300011

36. Kroenke K, Lawrence VA, Theroux JF, et al. Postoperative complications after thoracic and major abdominal surgery in patients with and without obstructive lung disease. Chest. 1993;104(5):1445-1451. doi:10.1378/chest.104.5.1445

37. Sandri A, Papagiannopoulos K, Milton R, et al. High-risk patients and postoperative complications following video-assisted thoracic surgery lobectomy: a case-matched comparison with lower-risk counterparts. Interact Cardiovasc Thorac Surg. 2015;21 (suppl_1):761-765. doi:10.1093/icvts/ivv204.146
38. Stamenovic D, Messerschmidt A, Schneider T. Surgery for lung tumors in the elderly: a retrospective cohort study on the influence of advanced age (over 80 years) on the development of complications by using a multivariate risk model. Int J Surg. 2018;52:141-148. doi:10.1016/j.ijsu.2018.02.008

39. Brunelli A, Fianchini A. Predicted postoperative FEV1 and complications in lung resection candidates. Chest. 1997;111(4):1145-1146. doi:10.1378/chest.111.4.1145

40. Nakahara K, Monden Y, Ohno K, et al. A method for predicting postoperative lung function and its relation to postoperative complications in patients with lung cancer. Ann Thorac Surg. 1985;39 (3):260-265. doi:10.1016/S0003-4975(10)62591-X

41. Kearney DJ, Lee TH, Reilly JJ, et al. Assessment of operative risk in patients undergoing lung resection. Importance of predicted pulmonary function. Chest. 1994;105(3):753-759. doi:10.1378/ chest.105.3.753

42. Wang J. Clinical value of perfusion lung scanning in the surgical treatment of lung cancer. Zhonghua Yi Xue Za Zhi. 1991;71:620-622, 644.

43. Cottrell JJ, Ferson PF. Preoperative assessment of the thoracic surgical patient. Clin Chest Med. 1992;13(1):47-53. doi:10.1016/S02725231(21)00836-4

44. Parisi GF, Cannata E, Manti S, et al. Lung clearance index: a new measure of late lung complications of cancer therapy in children. Pediatr Pulmonol. 2020;55(12):3450-3456. doi:10.1002/ppul.25071
Journal of Multidisciplinary Healthcare

\section{Publish your work in this journal}

The Journal of Multidisciplinary Healthcare is an international, peerreviewed open-access journal that aims to represent and publish research in healthcare areas delivered by practitioners of different disciplines. This includes studies and reviews conducted by multidisciplinary teams as well as research which evaluates the results or conduct of such teams or healthcare processes in general. The journal

\section{Dovepress}

covers a very wide range of areas and welcomes submissions from practitioners at all levels, from all over the world. The manuscript management system is completely online and includes a very quick and fair peer-review system. Visit http://www.dovepress.com/testimonials. php to read real quotes from published authors. 